\title{
Projetos agroecológicos no Pontal do Paranapanema: a visão de agricultores assentados e o papel das políticas públicas

\author{
Otávio Gadiani Ferrarini ${ }^{1}$ \\ Paulo Eduardo Moruzzi Marques ${ }^{2}$
}

RESUMo: A implantação de arranjos produtivos agroecológicos em assentamentos rurais tem sido uma aposta de diferentes atores visando à construção de um modelo agrícola que consiga gerar renda ao agricultor, manter o equilíbrio ambiental e garantir a coesão social. O presente artigo apresenta as motivações, reflexões e críticas de agricultores engajados em projetos agroecológicos desenvolvidos em assentamentos rurais no Pontal do Paranapanema - SP. A metodologia utilizada na pesquisa baseou-se, sobretudo, na realização de entrevistas semiestruturadas com 11 agricultores assentados beneficiários de projetos agroecológicos. Entretanto, de maneira complementar, também foram entrevistados outros atores relevantes à pesquisa como os técnicos e coordenadores dos projetos, pesquisadores e lideranças do MST. Os resultados sugerem que os projetos conseguiram modificar a dinâmica de produção das famílias beneficiárias para sistemas produtivos mais ecológicos. Em termos de política pública, a pesquisa evidenciou que estas desempenham um papel contraditório no que diz respeito ao estímulo a sistemas agroecológicos.

Palavras-Chave: Agroecologia; Assentamentos Rurais; Sistemas Agroflorestais; Multifuncionalidade da Agricultura.

ABSTRACT: The implementation of agroecological productive systems in rural settlements has been carried out by different stakeholders who seek to establish an agricultural model that can generate income for the farmer, maintain the environmental balance and ensure social cohesion. This paper presents the motivations, reflections and criticisms of farmers engaged in agroecological projects developed in rural settlements in Pontal do Paranapanema - SP. The methodology used in the research was mainly based on semi-structured interviews with 11 settled farmers engaged in agroecological projects. However, as a complement, other relevant stakeholders were also interviewed, such as project technicians, project coordinators, researchers and MST leaders. The results suggest that the projects succeeded in modifying the production dynamics of the beneficiary families to more ecological production systems. In terms of public policy, the research showed that it plays a contradictory role in the promotion of agroecological systems.

KEYwORDS: Agroecology; Rural settlements; Agroforestry Systems; Multifunctionality of agriculture.

\footnotetext{
'Engenheiro Florestal formado na Escola Superior de Agricultura "Luiz de Queiroz" da Universidade de São Paulo - ESALQ/USP (2010), possui mestrado pelo Programa de Pós-Graduação Interunidades de Ecologia Aplicada - ESALQ/USP e CENA (2014). Atualmente trabalha como Analista Ambiental do Ministério do Meio Ambiente, dentro do Departamento de Conservação de Ecossistemas na Secretaria de Biodiversidade. E-mail: otavioferrarini@hotmail.com

${ }^{2}$ Professor associado de Sociologia na Universidade de São Paulo (com ênfase em Sociologia Rural). Atua no Programa de Pós-Graduação Interunidades (CENA-ESALQ) em Ecologia Aplicada.E-Mail: pmarques@usp.br
} 


\section{INTRODUÇÃo}

O processo de modernização da agricultura e a difusão de um modelo agropecuário produtivista tomaram proporções globais. A visão de agricultura moderna sob um padrão fundado em insumos químico, moto-mecanização e modificação genética, transformada em um "pacote tecnológico" a ser reproduzido, foi difundida em todo mundo, criando uma nova racionalidade produtiva (ARL, 2009). Sob a justificativa de lidar com os problemas de insegurança alimentar agravados no período do pós-guerra, essa racionalidade produtivista da Revolução Verde tornou-se de fato o modelo hegemônico agrícola a nível mundial após a segunda metade do século XX.

Entretanto, no início do século XXI, dados alarmantes da FAO/ONU (Organização das Nações Unidas para Agricultura e Alimentação) de que aproximadamente 815 milhões de pessoas no mundo ainda sofrem com a fome (FAO, 2017) reforçam as críticas contra o modelo agrícola industrial. $\mathrm{O}$ insucesso deste último diz respeito aos diversos impactos ambientais e sociais, como a erosão de solos, a contaminação por agrotóxicos e a eutrofização pelo uso de adubos químicos dos cursos d'água, o aumento do número de pragas e doenças dos cultivos, a destruição de habitats naturais da fauna, a erosão genética e o aumento da instabilidade socioeconômica das comunidades de agricultores familiares (CROUCH, 1995 apud. SANTOS, 2012).

Essa situação alarmante coloca na ordem do dia propostas de construção de modelos de agricultura libertos dessa lógica industrial simplificadora, avançando para práticas ancoradas em dimensões socioambientais da agricultura. Segundo Ehlers (1996), esses novos modelos construídos na concepção de uma agricultura ecológica emergem para reduzir os problemas sociais, bem como a degradação da biodiversidade e dos recursos naturais do planeta, como solo, água, ar, fauna e flora. Efetivamente, os danos ao meio ambiente e ao homem provocados pelos sistemas convencionais de produção de alimentos são consideráveis. Essa constatação leva não somente ao debate e reflexão sobre uma reformulação tecnológica das práticas agrícolas, mas também sobre um completo redesenho dos princípios e das orientações da agricultura (ALTIERI, 1998). Nesta última ótica, um enfoque baseado unicamente na substituição de insumos seria uma visão restrita, que não superaria as verdadeiras limitações do atual modelo agrícola. Para autores engajados no debate por mudanças acentuadas da agricultura, a consolidação de novos agroecossistemas mais ecológicos não poderia acontecer sem uma mudança profunda das lógicas socioeconômicas que governam a produção agrícola (ALTIERI, 1998).

Dentre os fatores que podem induzir esta mudança, convém realçar o papel das políticas públicas enquanto força catalisadora de transformação ou manutenção 
do status quo. No Brasil, as políticas agrícolas foram adequadas e funcionais ao desenvolvimento urbano-industrial ligado de forma mais ou menos dependente ao mercado internacional (NETTO, 2011). Desse modo, o modelo de agricultura industrial, produtivista e de larga escala foi privilegiado, recebendo sustentação considerável por parte dos sucessivos governos. As políticas direcionadas à diversificação da produção, ao fortalecimento da agricultura familiar e a realização da reforma agrária não estiveram na pauta das diretrizes para a transformação agrícola.

Todavia, políticas públicas democráticas devem ser vistas como um processo de construção social que mobiliza atores distintos que disputam, dentro das estruturas de poder, espaço para defender seus interesses (BONNAL; LEITE, 2011). Efetivamente, desde o fim da ditadura militar, em meio a fortes disputas, o Estado torna-se pouco a pouco mais permeável a novas ideias e projetos políticos.

A criação do PRONAF (Programa Nacional de Fortalecimento da Agricultura Familiar), em 1995-96, é certamente um marco dessas mudanças. A formatação deste programa, o primeiro voltado especificamente para a agricultura familiar, ocorre graças à atuação intensa dos movimentos sociais e sindicais que, encampando lutas em favor da reforma agrária e do auxílio específico à agricultura familiar, exigiram uma ação pública efetiva em favor de suas reivindicações (LEITE, 2001).

De lá para cá mudanças no cenário político e no papel dos movimentos sociais levaram à consolidação da Política Nacional de Agroecologia e Produção Orgânica (PNAPO), um dos principais marcos legais voltados à agricultura ecológica atualmente no país. Instituída pelo Decreto n 7.794 de 20 de agosto de 2012 (BRASIL, 2012), essa política inclui a participação da sociedade civil em sua Comissão Nacional e tem como principal instrumento para sua implementação o Plano Nacional de Agroecologia e Agricultura Orgânica (PLANAPO).

Contudo, mesmo com avanços no sentido de construir um desenvolvimento rural diferenciado, essas mudanças nas políticas públicas têm encontrado diversos obstáculos que muitas vezes distanciam a concepção dos programas de sua execução e implementação real. Até que ponto as intenções de estímulo ao desenvolvimento de sistemas produtivos agroecológicos se concretizam constitui uma questão que precisa ser melhor discutida.

Um exemplo de incongruência se refere à execução orçamentária do PLANAPO 2013-2015. As ações previstas no Plano somavam uma previsão orçamentária de R \$ 8,8 bilhões (CIAPO, 2013). Entretanto, o valor de fato aplicado neste período para execução do PLANAPO foi de R\$ 2,9 bilhões, ou seja, apenas 33\% do montante incialmente previsto (CANDIOTTO, 2018). Os impactos desta baixa execução orçamentária podem interferir diretamente em projetos engajados com a transição 
agroecológica evidenciando a relação direta entre políticas públicas e projetos.

\section{OBJetivo}

Nesse sentido, o presente artigo analisa dois projetos agroecológicos que foram implementados em assentamentos rurais na região do Pontal do Paranapanema, no estado de São Paulo, com o objetivo de analisar seus impactos a partir da visão dos atores envolvidos, sobretudo dos agricultores beneficiados. O estudo buscou avaliar o caráter multifacetado dos impactos (positivos e negativos) dos sistemas de produção, atentando para a simultaneidade entre a produção de bens materiais (produtos e geração de renda) e não materiais (coesão social, equilíbrio ambiental) na agricultura.

Ademais, a pesquisa também buscou discutir em que medida os resultados desses sistemas produtivos foram potencializados ou limitados por diferentes políticas públicas. Nesse aspecto o estudo teve por objetivo analisar os reflexos dessas políticas públicas na dinâmica do território estudado, buscando verificar em que medida elas reconhecem e conferem legitimidade as iniciativas.

\section{Projetos Agroecológicos no contexto do Pontal do Paranapanema}

A região do Pontal do Paranapanema está localizada no Planalto Ocidental do estado de São Paulo, na confluência entre os rios Paraná e Paranapanema. Até o início do século $\mathrm{XX}$, esta região era inteiramente coberta por florestas tropicais de grande valor biótico. No entanto, a ocupação territorial dessas áreas, até então "selvagens", ocorreu com base em intensa derrubada da mata nativa, na expulsão das populações indígenas Caiuás e Caigangues e em massivo processo de grilagem de terras (LEITE, 1998).

Exemplo emblemático dessa ocupação foi o ataque permanente às reservas florestais implantadas na região: a "Reserva Florestal do Morro do Diabo"3, a "Reserva da Lagoa São Paulo"4 e a "Grande Reserva do Pontal"5. No total, essas três reservas abrangiam uma área de 297.340 ha quando estabelecidas (LEITE, 1998). Desde então, devido à forte influência dos grandes latifundiários sobre o poder público local, sobretudo durante o período da ditadura militar, essas áreas de reservas foram sendo ocupadas e desmatadas, gerando enorme redução das florestas da região. Atualmente, essa área florestal se limita sobretudo ao Parque Estadual do Morro do Diabo (PEMD), criado em 1986, que hoje apresenta uma área de 33.845,33 ha (IF/SMA/SP, 2006), e aos pequenos fragmentos florestais, em sua maioria menores do que 2.000 ha, dispersos ao longo da paisagem (DITT, 2002)

\footnotetext{
${ }^{3}$ Criada pelo Decreto Lei n ${ }^{\circ} 12.279$ de 29 de outubro de 1941 .

${ }^{4}$ Criada pelo Decreto Lei ${ }^{\circ} 13.049$, de 06 de novembro 1942.

${ }^{5}$ Criada pelo Decreto Lei no 13.075 de 25 de novembro 1942.
} 
Com esse histórico de ocupação, a região passou por ciclos econômicos diversos, como a exploração madeireira, o café, o algodão e, nas décadas de 70 e 80 , ocorre um avanço intenso da atividade pecuária, o que gerou um novo processo de concentração fundiária, com extinção de muitos postos de trabalho. Sobre esse processo, Feliciano (2009) sugere que as tentativas forjadas pelo Estado, desde o início do século XX, através de leis, decretos e procedimentos administrativos de discriminação de terras, foram mais para legitimar o desenvolvimento capitalista na região do que para resolver seus conflitos fundiários.

Esse contexto territorial, em panorama nacional de bloqueio da reforma agrária e de inexistência de uma política agrícola destinada ao apoio à agricultura camponesa durante as décadas de 70 e 80 (FERNANDES; RAMALHO, 2001), levaram milhares de sem terra da região a intensificarem sua organização social, consolidando movimentos sociais de luta pela terra, especialmente o Movimento dos Trabalhadores Rurais Sem-Terra (MST). Graças a uma forte ação política e social desses movimentos em meio a violentos conflitos, o território passa a abrigar diversos assentamentos rurais a partir da década de 90, o que, de certa forma, reconfigurou a ocupação territorial e abriu novas perspectivas produtivas.

Essas novas perspectivas concebem a Reforma Agrária além de seus objetivos óbvios de distribuição de terras e de desenvolvimento de classes médias no campo, também desempenhando um papel essencial no resgate de uma ocupação humana respeitosa da natureza (WHITAKER, 2009). Essa leitura é reforçada pela ideia segundo a qual os assentamentos abrem portas para o desenvolvimento de uma agricultura diferente dessa preconizada pela modernização conservadora, pois, mesmo que o assentado também seja “obrigado" a usar pacotes tecnológicos devido às pressões da racionalidade instrumental produtivista, sua dinâmica produtiva é fundada frequentemente em mosaicos complexos de diversidade agrícola, que, diferente das grandes propriedades com monoculturas, favorece maior preocupação e cuidado com o meio ambiente (WHITAKER, 2009)

Como exemplo evidente dessa reconfiguração de perspectiva, o discurso do MST, movimento social de luta pela terra mais representativo na região em estudo, migra de um enfoque com forte viés produtivista para outro mais aderente à visão agroecológica, incorporando ideias como respeito e resgate da agricultura camponesa sob modelo produtivo agroecológico (BORSATTO; CARMO, 2013). A partir de seu IV Congresso Nacional, realizado em 2000, o MST passa a integrar de forma explícita a agroecologia como base para a realização da reforma agrária no país, tratando-a não apenas como uma prática agrícola de contorno ecológico, mas envolvendo-a em um debate político e social de questionamento ao modelo 
produtivista da agricultura convencional (larga escala, altamente mecanizada, dependente de insumos agroquímicos e atrelada aos complexos agroindustriais) (BORSATTO; CARMO, 2013).

Nesse quadro, foram desenvolvidos muitos projetos produtivos de bases agroecológicas em assentamentos rurais da região com o intuito de fomentar a perspectiva de uma produção agrícola diversificada e multifuncional. Em nossa pesquisa, foram avaliados projetos que utilizaram os Sistemas Agroflorestais (SAFs) como modelo para a implantação de unidades de produção agroecológicas.

A aposta nos SAFs parte da ideia de que esses sistemas podem responder a um grande desafio dos assentamentos que consiste na possibilidade de harmonizar a relação entre produção e conservação. Ainda que muitos assentados reconheçam a importância ambiental, existem barreiras culturais, normativas, técnicas e econômicas para que tais exigências legais sejam cumpridas pelos agricultores (RODRIGUES et. al. 2007). Nesse sentido, os SAFs podem representar uma alternativa de estímulo econômico à recuperação florestal, levando à incorporação do componente arbóreo em estabelecimentos rurais (RODRIGUES et. al. 2007).

\section{BREVE DESCRIÇÃO DOS PROJETOS ESTUDADOS}

Neste estudo, foram escolhidos para análise dois projetos já consolidados de implantação de SAFs agroecológicos biodiversos e sucessionais: 1) o "Projeto Bioenergia com Biodiversidade e Segurança Alimentar" e, 2) o "Projeto Café com Floresta". Esses projetos foram desenvolvidos no mesmo território e contexto sócio-político. No entanto, foram executados por entidades diferentes, com métodos diversos e em períodos distintos, resultando SAFs com diferentes idades e objetivos, o que nos fornece um rico cenário para os objetivos de nossa pesquisa.

O Projeto "Bioenergia com Biodiversidade e Segurança Alimentar" foi desenvolvido pelo Programa de Pesquisa para o Desenvolvimento de Assentamentos Rurais e Agricultura Familiar (PPDARAF), do Núcleo de Apoio à Cultura e Extensão em Educação e Conservação Ambiental da USP (NACE - PTECA/ ESALQ/USP), com financiamento do então Ministério do Desenvolvimento Agrário - MDA ${ }^{6}$ através da Secretaria da Agricultura Familiar (SAF) como parte do "Programa Nacional de Produção e Uso do Biodiesel" (PNPB) 7 . Esse projeto,

\footnotetext{
${ }^{6}$ A partir da publicação da Lei n 13.502/2017 que estabelece a organização básica dos órgãos da Presidência da República e dos Ministérios, o Ministério do Desenvolvimento Agrário deixou de existir e hoje esse assunto é tratado pela Secretaria Especial de Agricultura Familiar e do Desenvolvimento Agrário, ligada à Casa Civil da Presidência da República.

${ }^{7} \mathrm{PNPB}$, segundo site oficial da Secretaria Especial de Agricultura Familiar e Desenvolvimento Agrário, é um programa interministerial do Governo Federal, criado em 2004, que objetiva a implementação de forma sustentável, tanto técnica como econômica, da produção e uso do biodiesel, com enfoque na inclusão social e no desenvolvimento regional, via geração de emprego e renda.
} 
assinado no final de 2008, teve, segundo seu documento base, o objetivo geral de contribuir com o desenvolvimento de novos sistemas produtivos no campo, com foco na produção de biocombustíveis, na diversificação da produção, nos sistemas agroflorestais, no manejo da biodiversidade e na segurança alimentar, com base na participação social e na construção da autonomia dos agricultores.

Para atingir este objetivo, a equipe executora implantou unidades de Sistemas Agroflorestais biodiversos em assentamentos rurais no Pontal do Paranapanema, utilizando a Macaúba (Acrocomia sp.) como espécie chave visando a produção de biodiesel e geração de renda. Além desta palmeira, foram plantadas frutíferas diversas e culturas anuais com o intuito de promover a geração de renda e a segurança alimentar das famílias, junto com árvores de espécies nativas com o intuito de recompor a biodiversidade no sistema.

O projeto foi executado a partir de meados 2009 até o início de 2012, totalizando um período de quase dois anos e meio de atividades. Ao longo desse tempo, foram realizadas diversas atividades de formação, viagens técnicas e capacitação dos agricultores em temas relevantes, com o intuito de promover a implantação de dez (10) Áreas Experimentais Demonstrativas com SAFs, para a produção de "Bioenergia com Biodiversidade e Segurança Alimentar".

A implantação dessas áreas de SAFs ocorreu nos lotes de 10 famílias assentadas em quatro assentamentos localizados no município de Mirante do Paranapanema. Desse modo, foram implantados SAFs em lotes de famílias dos seguintes Projetos de Assentamentos (PA): Margarida Alves (4), Roseli Nunes (3), Antônio Conselheiro (2) e Paulo Freire (1).

O Projeto "Café com Floresta" foi desenvolvido pela ONG Instituto de Pesquisas Ecológicas (IPE) que, desde 1992, tem grande atuação na região do Pontal com projetos socioambientais. O "Café com Floresta" teve seu início no ano de 2001 visando a implantação de Sistemas Agroflorestais diversificados, que associam a produção cafeeira com cultivos anuais diversos e com o plantio de espécies de árvores nativas da Mata Atlântica.

As áreas de café com floresta foram implementadas principalmente em assentamentos próximos a fragmentos florestais (sobretudo nos arredores do Parque Estadual do Morro do Diabo), objetivando desempenhar o papel de "trampolins ecológicos" (GANDARA; KAGEYAMA, 2001), ou seja, formando uma paisagem de bosques florestais que permitiriam o trânsito de algumas espécies da fauna e flora entre um fragmento e outro, com vistas a favorecer o fluxo gênico e aumentar a diversidade genética nestes locais (IPE, 2018). Além desse aspecto ecológico, o projeto também objetivou contribuir para a 
geração de renda das famílias assentadas a partir de atividades produtivas mais sustentáveis, consolidando práticas que permitam a otimização do uso dos recursos naturais disponíveis no estabelecimento dos assentados. Suas ações foram fundadas em atividades de formação, com método que visou tanto o debate dos temas nas comunidades quanto maior independência do agricultor.

A opção pela utilização do café como espécie chave destes SAFs objetivou garantir consequente geração de renda a fim de promover um incentivo financeiro ao agricultor inserido no projeto. Nesse sentido, o café representa efetivamente uma boa alternativa de renda, uma vez que esse produto possui um mercado já muito bem estabelecido. Além deste aspecto, estudos indicam que o plantio de café em associação com árvores proporciona condições microclimáticas mais amenas, favorecendo o desenvolvimento e a produção das plantas, promovendo proteção contra geadas, reduzindo a bienalidade produtiva, podendo também reduzir os custos de produção e aumentar a diversidade, resiliência e auto-suficiência dos agroecossistemas (LOPES et. al. 2014).

É difícil precisar o número de agricultores que implantaram sistemas de "Café com Floresta" na região, entretanto, segundo Lima e colaboradores (2007), no referido ano existiam 38 famílias participantes do projeto, distribuídas em sete assentamentos, que implantaram em média um hectare de "café com floresta" cada uma.

\section{Metodologia da Pesquisa}

Conforme mencionado, a pesquisa optou por analisar dois projetos distintos de implementação de SAFs. Esta opção permitiu construir uma análise mais abrangente, de modo a não restringir as interpretações do estudo às singularidades de um único projeto.

Para a construção da análise sob a perspectiva dos agricultores assentados, foram entrevistados ao todo 11 agricultores, dos quais 5 participaram do projeto "Bioenergia com Biodiversidade e Segurança Alimentar" e 6 participaram do projeto “Café com Floresta". Como a intenção do estudo não foi avaliar os projetos em si, mas sim os SAFs implantados pelos projetos e seus reflexos na vida dos agricultores, foram escolhidas para serem entrevistadas as famílias nas quais os SAFs tiveram um resultado positivo, e não todas as famílias envolvidas nos projetos.

A escolha das famílias fundou-se no cruzamento das informações de diferentes técnicos executores dos projetos. A partir das respostas sobre quais agricultores tiveram bons resultados nos projetos, foram escolhidos para a pesquisa aqueles melhores situados segundo as indicações dos técnicos. Essa metodologia se repetiu 
com os agricultores durante as entrevistas, através de perguntas a cada um deles sobre os resultados de outros agricultores que participaram do projeto. Por fim, essa triangulação de informações levou às 11 famílias consideradas nessa pesquisa.

As entrevistas, de modo geral, foram feitas com o chefe da família, na maioria dos casos o pai. Entretanto, a participação das mulheres e dos jovens era sempre estimulada. Assim, em alguns casos, esta presença ocorreu, o que foi de grande valia para o enriquecimento da pesquisa. Após a entrevista, foi realizada uma visita às áreas onde foram implantados os SAFs com o intuito de verificar in loco elementos que pudessem enriquecer ou confrontar os dados levantados nas entrevistas.

No âmbito do projeto "Bioenergia com Biodiversidade e Segurança Alimentar" as 5 famílias entrevistadas estavam localizadas nos Projetos de Assentamento do munícipio de Mirante do Paranapanema da seguinte forma: 2 famílias no PA Roseli Nunes; 1 família no PA Margarida Alves; 1 família no PA Antônio Conselheiro; 1 família no PA Paulo Freire.

Já no contexto do projeto "Café com Floresta” as 6 famílias entrevistadas estavam localizadas nos Projetos de Assentamento da seguinte forma: 1 família no PA São Bento IV, localizado em Mirante do Paranapanema; 2 famílias no PA Santa Rita da Serra; 2 famílias no PA Vale Verde; 1 família no PA Santa Teresinha da Água Sumida, localizados no município de Teodoro Sampaio.

Por fim, para complementar a análise, foram realizadas entrevistas com outros atores locais envolvidos de forma direta ou indireta com os projetos. Foram realizadas no total mais 9 entrevistas sendo elas: com dois técnicos do ITESP (Fundação Instituto de Terras do Estado de São Paulo) envolvidos com projetos dessa natureza; com um antigo técnico do INCRA (Instituto Nacional de Colonização e Reforma Agrária) engajado nos dois projetos estudados; com um pesquisador da APTA (Agência Paulista de Tecnologia dos Agronegócios) de Presidente Prudente; com um dirigente regional do MST; com dois técnicos da ESALQ/USP que atuaram no projeto "Bioenergia com Biodiversidade e Segurança Alimentar" e com dois técnicos do IPE que atuaram no projeto "Café com Floresta".

\section{MOTIVAÇÕES E CRÍTICAS EM TORNO DOS PROJETOS AGROECOLÓGICOS: O OLHAR} DOS AGRICULTORES ASSENTADOS

A partir das entrevistas com as onze famílias assentadas buscou-se construir uma análise sobre suas motivações para se inserirem nos referidos projetos, bem como as suas críticas ao desenvolvimento das atividades. Foram solicitadas aos agricultores informações sobre experiências anteriores com produção agroecológica, motivações e expectativas em relação ao projeto, opiniões sobre a condução do projeto por 
parte da equipe técnica e um balanço dos resultados alcançados.

No universo deste estudo, todos os onze os agricultores manifestaram que não tinham nenhuma experiência anterior com produção agroecológica. Foram os técnicos que apresentaram concepções sobre esta última que era uma novidade para nossos entrevistados. Assim, os motivos que levaram esses agricultores a se interessarem por participar dos projetos não se associam com um conhecimento prévio incorporado sobre a agroecologia.

De fato, em quatro casos, os agricultores mencionaram que suas motivações iniciais se associavam à ausência de gastos financeiros na implantação dos SAFs, uma vez que todos os insumos utilizados foram fornecidos graças aos fundos dos projetos. Como não teriam gastos financeiros, consideraram que eram poucas as chances de terem perdas caso o projeto não oferecesse bons resultados. Outros três agricultores afirmaram que a principal motivação foi o fato de já terem trabalhado com a produção de café, desejando retomar essa atividade. Os demais agricultores apresentaram outras motivações: o projeto seria uma boa oportunidade para produzir frutas no lote, o que era uma vontade antiga de um dos assentados; em dois casos, o sistema agroflorestal poderia recompor com árvores a área ao redor da casa, para cumprir a legislação e proteger o local e; a experiência apresentada em vídeo estimulou outro assentado a decidir tentar algo parecido em seu sítio.

Por outro lado, sete agricultores dos onze entrevistados alegaram que estavam receosos com relação às ideias previstas nos projetos, pois eram relativamente céticos vis-à-vis a agroecologia. Apenas quatro assentados desde o início consideravam a ideia interessante e estimulante.

Esse quadro revela que, na maioria dos casos, os agricultores se inseriram no projeto por motivos não diretamente relacionados ao interesse por desenvolver uma produção agroecológica. Dos quatro que consideravam a ideia interessante, apenas três agricultores apresentaram motivos mais relacionados ao desejo de desenvolver sistemas que pudessem conciliar as esferas produtivas e ecológicas.

Essa interpretação de certa forma foi reforçada pelas respostas dos agricultores quando indagados sobre suas expectativas com o projeto. Dos onze agricultores, seis declararam que esperavam produzir bem para vender (sejam culturas anuais, frutas, café ou leite). Outros dois assentados manifestavam expectativas modestas: "qualquer resultado positivo já seria satisfatório" e o desejo de "mais o aprendizado do que a produção em si".

Apenas três agricultores mencionaram esperar como resultado a composição de um sistema produtivo que ao mesmo tempo servisse para recuperar a mata na região. A partir dessas respostas, é possível observar que os principais resultados 
esperados com os projetos giravam em torno de um retorno produtivo e econômico a partir da implantação dos SAFs, o que demonstra a grande relevância dessa questão no universo destes agricultores assentados nesse estudo. Efetivamente, estes últimos possuem pouca margem de manobra para a realização de experiências cujos resultados não contribuam com meios para melhorar suas condições frequentemente precárias de vida.

Como apresentado anteriormente, a atuação dos técnicos em ambos os casos foi o suporte fundamental para o desenvolvimento dos projetos visando tanto construção de conhecimento agroecológico, teórico e prático, junto aos agricultores, quanto a implantação das áreas de SAF. A mobilização de metodologias participativas foi assim essencial. Desse modo, a pesquisa procurou levantar junto aos agricultores suas impressões com relação ao acompanhamento técnico nos projetos e seus reflexos.

Quando questionados sobre este acompanhamento durante a execução dos projetos, seis agricultores consideraram ter havido um bom desempenho, tanto na frequência de visitas técnicas quanto em sua participação em atividades chaves de implantação dos SAFs. Já quatro agricultores avaliaram o acompanhamento técnico bom apenas no começo, mas, após o estabelecimento inicial dos SAFs, os técnicos se ausentaram por longos períodos, o que dificultou o desenvolvimento destas áreas de produção agroflorestal. Apenas um agricultor julgou como ruim o acompanhamento, considerando que os técnicos quase nunca estiveram em seu sítio, o que, em sua opinião, prejudicou a implantação e consolidação de seu sistema.

Quanto ao planejamento das áreas no que diz respeito à escolha das espécies, espaçamento entre plantas, arranjos do sistema, local e métodos de plantio, nove agricultores avaliaram que principalmente os técnicos tomaram as decisões. Apenas dois agricultores estimaram que o planejamento foi realizado de forma conjunta, a partir do diálogo entre técnicos e agricultores. Essa avaliação revela um distanciamento entre a proposta metodológica dos projetos, que ressaltava a construção participativa, e sua execução. Efetivamente, a partir do ponto de vista dos agricultores, é possível inferir que essa construção não foi tão participativa como pretendia ser.

Com relação ao acompanhamento na implantação dos sistemas agroflorestais, seis agricultores consideraram que esse período foi muito bom, ressaltando o envolvimento técnico tanto na organização das tarefas, como também em sua execução, inclusive em termos de contribuições nos trabalhos braçais de plantio. Os outros cinco agricultores avaliaram que a participação dos técnicos na fase de implantação foi boa, mas pouco voltada para a execução, sendo mais uma 
contribuição organizativa e teórica, do que prática.

Nota-se que, na fase mais inicial dos sistemas, o acompanhamento técnico em ambos os casos foi bem presente. Entretanto no que diz respeito ao acompanhamento técnico após o estabelecimento das áreas, as avaliações foram em outro sentido. Cinco agricultores consideraram esse acompanhamento como ruim, estimando que houve uma total ausência dos técnicos nessa fase. Outros quatro avaliaram como regular, pois tiveram um acompanhamento muito pontual. Apenas dois julgaram que tiveram um bom apoio técnico na fase de manejo e condução dos sistemas. Essas ausências de suporte na visão dos agricultores evidenciam uma das principais dificuldades na execução de projetos agroecológicos pontuais, ou seja, a descontinuidade das ações. Na maioria dos casos, os projetos preveem apenas a implantação dos sistemas, não garantindo um acompanhamento no longo prazo.

Por fim, quando interrogados sobre o alcance dos resultados esperados, três agricultores manifestaram positivamente, pois os consideram integralmente alcançados, estando satisfeitos. Apenas um agricultor estimou que o projeto não atingiu os resultados esperados, o que foi associado à interrupção de sua implantação em razão de ter sido abandonado pelos técnicos no seu ponto de vista. Os sete outros agricultores avaliaram que o projeto atingiu parcialmente os resultados na medida em que esperavam obter uma produção melhor do que aquela alcançada com o sistema. As principais razões consideradas para explicar este resultado parcial foram: problemas climáticos (como geadas e estiagem), dificuldade de manejo (notadamente com eventos de ataque de pragas e falta de acompanhamento técnico quando necessário) e; insuficiência do trabalho destinado aos SAFs pela própria família, uma vez que estes sistemas demandam muita mão de obra.

\section{O PAPEl das POLÍTICAS PÚblicas No CONTEXTO dOS PROJETOS}

Como já apresentado, os projetos agroecológicos em questão representam ações pontuais dentro de um quadro territorial em que prevalece o modelo de agricultura industrial produtivista. Assim, tratam-se de projetos-piloto servindo de referências para agriculturas emergentes no território.

Nesse contexto, podemos considerar que, para ganhar escala e tornar essas experiências um modelo de produção, é imprescindível que as políticas públicas relacionadas à produção agrícola na região desempenhem um papel de alavancagem dos resultados desses projetos. De fato, uma das definições mais gerais de políticas públicas considera que sua função é solucionar os problemas e desafios existentes em determinado momento histórico, através de um conjunto de ações que produzirão um efeito específico (SOUZA, 2006). 
Nossa investigação buscou levantar elementos sobre políticas públicas aplicadas nos assentamentos da região em três esferas: o crédito, a comercialização e a assistência técnica. A partir desses elementos, foi analisado em que medida essas políticas conseguem realmente impulsionar a promoção de um modelo de desenvolvimento rural que incorpore novos temas, como a agroecologia, na região.

Dentre os agricultores entrevistados, sete relataram que pelo menos durante algum momento de suas trajetórias, já estiveram inadimplentes por não conseguirem quitar os contratos de crédito estabelecidos. Os motivos que explicam esses resultados são os mais diversos, o que foi analisador por Guanziroli (2007) considerando o PRONAF (principal linha de crédito acessada por assentados rurais). Este autor enfatiza aspectos como a falta de assistência técnica e sua baixa qualidade; a dificuldade de gerenciamento dos recursos do crédito por parte dos agricultores; a falta de visão sistêmica dos técnicos que muitas vezes apostam em projetos restritivos e pouco dinâmicos; as dificuldades de integração ao mercado e a falta de estruturas que contribuam na comercialização.

O histórico de tomada de financiamentos para desenvolver a produção leiteira, o que ocorre ou ocorreu com todos os agricultores entrevistados, deve ser profundamente considerado. Trata-se de refletir sobre os motivos da consolidação da produção leiteira como principal atividade na região. Alguns dos entrevistados relataram que essa atividade era "recomendada" pelos técnicos, diagnosticando que os lotes só serviam para pastagem e não para agricultura. Outros reforçam este argumento evocando que, em nenhum momento, sobretudo no início da ocupação dos lotes, outra alternativa produtiva lhes foi apresentada como possível de ser financiada. Portanto, o leite acabou sendo a única proposta em discussão.

Esse fenômeno pode ser interpretado com o apoio no que Guanziroli (2007) define como "falta de visão sistêmica dos técnicos", evidenciando muitas vezes divergências entre as propostas dos técnicos e as aspirações dos agricultores. Esta postura dos técnicos tende a padronizar um modelo produtivo da reforma agrária no Pontal do Paranapanema a partir de um mito segundo o qual a região naturalmente possui uma aptidão para a produção leiteira. Essa aptidão, mesmo que fundamentada nas características agrícolas da região, foi também construída a partir de diretrizes que norteavam a assistência técnica no início da implantação dos assentamentos na região. Estas últimas eram reflexo de uma visão ancorada nas facilidades de enquadramento e aceitação dos projetos de crédito para a produção leiteira.

A pesquisa de Oliveira e Bergamasco (2014) revelou situação similar em que a pecuária leiteira se consolidou como principal atividade produtiva de assentamentos em um município do norte do estado do Mato Grosso. A razão se refere ao papel 
desempenhado pelos projetos de créditos do PRONAF elaborados pelos técnicos de ATER, mesmo que boa parte dos agricultores não tivesse experiência com esse tipo de produção.

Independente dos motivos que levaram a essa situação nos assentamentos do Pontal do Paranapanema, o estabelecimento dessa matriz produtiva de leite levou à consolidação da ideia de que para viver em um sitio na região é preciso produzir leite, uma vez que sua venda é garantida. Como os assentados mesmo mencionam "é um dinheiro pouco, mas que todo mês pinga". Produzir leite não é um problema em si, mas as representações em torno desta produção representam sem dúvida um entrave na aceitação de outras propostas produtivas para os assentados da região.

A partir de 2003, foram criadas novas linhas de financiamento no PRONAF, sobretudo as linhas Floresta e Agroecologia, que abriram possibilidades de utilização do crédito agrícola para o desenvolvimento de sistemas produtivos mais ecológicos. No entanto, avalições apontam que o montante de recursos destinados para essas linhas foi muito reduzido quando comparado ao montante geral do recurso do programa. Segundo Sambuichi e Oliveira (2011), o PRONAF Agroecologia financiou, ao longo de cinco safras (2005-2006 a 2009-2010), um total de R\$11,4 milhões em 979 contratos, enquanto o total financiado pelo PRONAF Floresta, em seis safras analisadas (2004-2005 a 2009-2010), foi de R \$ 75,0 milhões, em 14.927 contratos. A tabela 1 evidencia o quão pouco foi o recurso destinado às linhas Agroecologia e Floresta, em comparação ao montante gerido pelo PRONAF nesse mesmo período (R \$ 20,1 bilhões).

Tabela 1 - Montante de recursos PRONAF (safras 2004/05 - 2009/10).

\begin{tabular}{l|l|l}
\hline PRONAF - TOTAL & R $\$ 20,1$ bilhões & $100 \%$ \\
\hline PRONAF Agroecologia & $\mathrm{R} \$ 11,4$ milhões & $0,06 \%$ \\
\hline PRONAF Floresta & $\mathrm{R} \$ 75,0$ milhões & $0,37 \%$ \\
\hline
\end{tabular}

Fonte: Adaptado de Sambuichi e Oliveira (2011).

Esses dados relacionados ao recurso destinado a essas linhas do programa nos permitem inferir sobre a pouca efetividade do PRONAF na consolidação de sistemas produtivos de base agroecológica, principalmente os SAFs. Técnicos entrevistados alegaram que a complexidade desse tipo de sistema (SAFs) torna muito difícil tanto a elaboração de projetos desse tipo, como a sua apreciação e aprovação pelo banco, cujos critérios de análise se fundam prioritariamente em aspectos econômicos. Logo quanto mais simplificado o sistema, mais simplificada a elaboração do projeto com seus custos e projeções de retorno. 
Exemplo disso, o PRONAF Florestal que, até a safra de 2006-2007 permitia o financiamento para o cultivo de espécies exóticas e monocultivos florestais em geral, apresentou um orçamento de R \$ 25,3 milhões na safra 2006-2007. Porém, a partir de 2007 passou a direcionar os financiamentos principalmente para Sistemas Agroflorestais e com essa mudança, o volume de recursos destinados a essa linha também se alterou chegando na safra 2009-2010, ao montante de R \$ 5,9 milhões. Esta redução no volume de recurso nos permite pensar que, no primeiro período mencionado, a maior parte dos financiamentos foi utilizada para implantação de monoculturas e não para o desenvolvimento de sistemas florestais mais biodiversos (SAMBUICHI; OLIVEIRA, 2011).

Com relação ao PRONAF Agroecologia, também não foi possível, ao longo da pesquisa de campo concluída em 2014, mapear nenhuma experiência regional de desenvolvimento de sistemas desse tipo a partir dessa linha de financiamento. Efetivamente, a pouca quantidade de contratos em todo o Brasil nessa linha explica tal ausência, ainda mais que as regiões Centro-Oeste, Sul, Norte e Nordeste foram as que receberam os maiores volumes de recursos nas safras de 2005-2006 a 20092010. O destaque cabe à região Norte, que recebeu o maior volume de recursos no total do período ( $40 \%$ do total financiado), sendo a maior parte apenas para o estado do Pará (R\$ 4,4 milhões) (SAMBUICHI e OLIVEIRA, 2011).

Segundo Fávero (2007), os principais desafios do acesso ao PRONAF agroecologia, considerando estudo de caso mineiro, foram: i) a resistência por parte dos agentes estatais em aceitar um financiamento focado em sistemas de produção de modo mais integral e não de modo restrito a uma única cultura, como é o mais comum; ii) o formato do sistema de crédito onde os itens financiáveis estão voltados para produtos e se restringem a determinados insumos e equipamentos e; iii) o limite de crédito que não está adequado a projetos mais complexos e de mais longo prazo, como aqueles de base agroecológica.

Com a falta de efetivação dessa linha de financiamento na região em estudo, os poucos sistemas de base agroecológica desenvolvidos em assentamentos do Pontal só foram possíveis devido à execução de projetos como aqueles analisados nesse trabalho. Portanto, tratam-se de experiências pioneiras muito interessantes, porém pontuais em termos de representatividade na realidade agropecuária regional devido a carência de políticas estruturantes que permitam avançar para soluções mais ajustadas à realidade de vida dos agricultores.

Como já abordado, as políticas de crédito destinadas especificamente para esses sistemas produtivos têm gerado poucos frutos na região. No entanto, quando indagados sobre a existência de políticas atuais que contribuam de alguma forma 
para a ampliação dessas iniciativas, todos os atores entrevistados identificaram lacunas nas políticas de crédito, mas mencionaram como muito promissoras as políticas de comercialização para mercados institucionais, sobretudo o Programa de Aquisição de Alimentos (PAA) e o Programa Nacional de Alimentação Escolar (PNAE).

Mesmo que direcionadas apenas à questão da comercialização, essas políticas permitiram aos agricultores um escoamento de produtos muito vantajoso, possibilitando a venda de produtos antes tidos como marginais dentro da organização produtiva dos lotes. Na opinião de um dos técnicos executores do Projeto Café com Floresta, atualmente o PAA e PNAE têm contribuído muito pois dão uma resposta de mercado para a produção em SAFs, onde normalmente se produz em grande diversidade mas em pequena escala, dificultando o escoamento da produção. Nota-se com essa afirmação que os programas contribuíram na superação dos investimentos exclusivos em produção em escala, o que sempre representou um entrave na comercialização desses assentados, e também indiretamente estimulou a diversificação produtiva do lote, pois o agricultor passou a valorizar essa diversidade a partir da possibilidade de venda dos produtos que antes eram encarados de maneira marginal dentro de seus lotes (quintais, pequenos pomares e hortas para autoconsumo) (LE MOAL, 2013).

No estado de São Paulo, dados de Le Moal (2013), indicam que no ano de 2008, os assentados do estado corresponderam a $46 \%$ dos fornecedores do Programa PAA na modalidade doação simultânea, valor bem acima da média nacional de apenas 14\%. Especificamente no caso dos assentados do Pontal do Paranapanema, entre os anos de 2008 e 2011, os acessos ao PAA giraram em torno de $10 \%$ do número de assentados no Pontal, ou seja, por volta de 625 famílias. O ano de 2009 se destaca pois cerca de $25 \%$ das famílias assentadas na região (por volta de 1560 famílias) foram atendidas (LE MOAL, 2013). No grupo de assentados considerados aqui, apenas três agricultores, dentre os onze entrevistados, acessaram esse programa, revelando que mesmo estimulando ações em prol da diversificação produtiva e da produção agroecológica, essa política ainda não é acessada por boa parte dos agricultores locais.

O papel desses programas de compras públicas como catalisador de sistemas de produção mais ecológicos, além de seu estímulo à diversificação produtiva, também se refere a seu incentivo à produção orgânica e agroecológica através do aumento do preço de aquisição desses produtos em até $30 \%$ sobre os convencionais, de acordo com a Resolução $n^{\circ} 12$ de 21 de maio de 2004 (BRASIL, 2004). Esse estímulo tem sido visto com bons olhos pelos diferentes atores e motiva os agricultores a desenvolver esses modelos produtivos. 
Convém insistir que essas políticas preveem apoio apenas à etapa final da produção que é a comercialização dos produtos. Logo, estão, em grande medida, desvinculadas de aspectos mais técnicos ligados ao desenvolvimento dos sistemas produtivos. Assim, tais programas possuem uma capacidade limitada de promover mudanças estratégicas em termos de favorecer modelos de produção alternativos.

Nesse ponto, é oportuno voltar o olhar para o papel desempenhado pela assistência técnica pública, considerando nesta análise o órgão estadual (ITESP) e federal (INCRA) responsável pala ATER na região. Dentre os agricultores entrevistados, nove avaliaram de maneira negativa a assistência técnica em seus lotes, afirmando que as visitas sempre foram muito pontuais e descontínuas. Deste ponto de vista, os técnicos contribuíram pouco com o desenvolvimento do lote como um todo e, em diversos casos, apareciam quando "já era tarde demais", acarretando perdas produtivas. A mudança frequente de técnicos dos assentamentos também foi avaliada como um fator negativo. Apenas dois agricultores afirmaram que recebiam visitas frequentes dos técnicos e consideravam a assistência técnica positiva, pois tinham suas demandas atendidas.

Quando indagados a respeito da participação dos técnicos dos órgãos de ATER nas atividades voltadas para a implantação e condução dos projetos de SAFs aqui estudados, bem como no auxílio aos agricultores com relação a esses projetos, todos os onze entrevistados estimam que os técnicos não contribuíram em nenhum momento para a condução dos projetos. Em alguns casos, os agricultores manifestaram que os técnicos nem sabiam da existência do projeto, mas em outros, eles afirmaram que os técnicos mesmo não auxiliando na condução das áreas de SAFs, muitas vezes levavam pessoas para visitar as áreas e as consideravam como um exemplo a ser seguido.

Esses aspectos refletem as dificuldades estruturais existentes dentro das políticas de Assistência Técnica e Extensão Rural. Essas questões foram também evidenciadas em entrevista com um dirigente regional do MST que afirmou que a ATER feita com base em chamadas públicas é deficiente pois: i) as agências que prestam serviço estão desvinculada da realidade em que vão atuar, ii) os contratos tem data para começar e terminar e normalmente esses prazos são curtos, iii) existem as metas institucionais que devem ser cumpridas e comprovadas, o que fazem os técnicos ficarem mais preocupados em cumpri-las do que em elaborar uma proposta que leve em consideração elementos estratégicos para desenvolver a agroecologia nos assentamentos.

A crítica ao mecanismo de chamadas públicas para a realização da assistência técnica nos assentamentos rurais também foi reforçada, ao longo do período do 
estudo, nos espaços coletivos de discussão sobre essa temática no âmbito do Conselho de Desenvolvimento Territorial do Pontal do Paranapanema (CODETER). Este tipo de manifestação ocorreu sobretudo no I Fórum de Avaliação dos Programas de Assistência Técnica e Extensão Rural do Território do Pontal do Paranapanema, realizado no dia 13 de março de 2013 no auditório da UNESP de Presidente Prudente.

Voltando ao foco sobre o papel da ATER na consolidação da agroecologia no território, para além da falta de uma assistência técnica mais atuante sentida pela maior parte dos agricultores, a falta de formação dos técnicos nessa área também foi um problema considerado tanto pelos próprios técnicos como pelos demais atores envolvidos com o desenvolvimento rural na região.

Essas críticas são apresentadas também em outros estudos sobre essa temática. Moraes e colaboradores (2013), estudando a realidade da aplicação da PNATER na região de Andradina/SP, revelaram, a partir da avaliação dos assentados locais, que a assistência técnica regional era caracterizada por processos de formação descontínuos; pela dificuldade de acesso aos profissionais, sobretudo, pela falta de visitas aos lotes de forma individualizada e por sua atuação fiscalizadora que muitas vezes se sobrepunham a suas ações de assistência técnica. Além destas insuficiências, também foram evidenciados os limites de atuação dos profissionais para a proposição de uma agricultura de base ecológica (como prevê a PNATER) uma vez que, na maioria dos casos, têm sua atuação e formação voltada para as formas convencionais de produção.

Os estudos de Taveira e Oliveira (2008) apresentaram análises similares. Os autores, estudando o atendimento as expectativas de assentados rurais do Pontal do Paranapanema com relação à assistência técnica local, levantaram como principais críticas endereçadas aos técnicos e órgãos de ATER: a ênfase na fiscalização, a realização de tarefas burocráticas ou somente de assistência técnica específica e pontual; o tamanho reduzido e instável da equipe e; a qualificação profissional insuficiente, com vistas a uma atitude compreensiva e compromissada dos técnicos com os assentados.

Esses estudos, inclusive o nosso, revelam a distância entre o discurso renovador existente na PNATER, elaborada inicialmente em 2004 a partir de um processo participativo de construção e instituída pela Lei N ${ }^{0} 12.188$, de 11 de janeiro de 2010 (BRASIL, 2010), e seus mecanismos de execução prática ainda presos aos velhos dogmas difusionistas (TAVEIRA; OLIVEIRA, 2008). Essa lógica difusionista, que historicamente fundamentou as ações de assistência técnica no Brasil, funda-se, de maneira resumida, na ideia de que a inovação tecnológica produzida nos centros de 
pesquisa deveria ser levada aos agricultores de maneira clara e eficaz pela atuação dos profissionais da ATER (MORAES et. al., 2013). Buscando se afastar dessa lógica, em sua descrição, a PNATER propõe a adoção de um paradigma baseado na produção ecológica, com abordagem multidisciplinar e enfoques metodológicos participativos. Entretanto, como indicado nos estudos mencionados, essa política ainda herda toda a estrutura e processo formativo de seus quadros que justamente colocam em xeque essa intenção (VALENTE, 2009).

Mesmo com essas dificuldades estruturais, os técnicos dos órgãos de assistência técnica que foram entrevistados nesse estudo demonstraram grande interesse pessoal em se qualificarem nessas temáticas propostas pela PNATER. A propósito, relatam a participação voluntária em diversos cursos, projetos e experiências que abordem esses temas e encaram essa formação como um grande desafio em suas profissões. Portanto, a agroecologia e produção orgânica não são tratadas como elementos fundamentais no âmbito dos órgãos executores das políticas de ATER, sendo executadas pontualmente apenas por técnicos mais pré-dispostos e motivados no sentido de construção de uma agricultura ecológica diferenciada.

\section{CONSIDERAÇÕES FINAIS}

Os modelos agroecológicos de produção são em princípio capazes de conciliar as funções ambientais, econômicas e sociais da agricultura. Entretanto, a partir dos resultados apresentados em nossa pesquisa, são realçados diversos problemas a serem superados na implantação de SAFs através de projetos, representando uma série de desafios.

O primeiro consiste em garantir que estes sistemas possam atender as expectativas dos agricultores envolvidos. Foi apresentado nos casos estudados que poucos agricultores se inserem em projetos desse tipo com uma clareza a respeito da agroecologia. Assim, na maioria dos casos, suas expectativas giram, sobretudo, em torno dos resultados produtivos e econômicos do sistema, o que é obviamente esperado ainda mais quando se trata de famílias com muitas dificuldades. Logo, o desenvolvimento de projetos desta natureza requer equalizar seus resultados ambientais e sociais com aqueles produtivos e econômicos.

Ademais, é grande a importância atribuída à criação de espaços de construção coletiva do conhecimento agroecológico nesses projetos. Como examinado, nenhum agricultor considerado no estudo tinha conhecimento anterior sobre o tema, mas a maioria adotou as ideias apresentadas desde o início do projeto e buscou executálas da melhor maneira possível. Porém, ainda foram identificadas insuficiências no estímulo à participação dos assentados. 
Nos casos estudados, uma limitação intrínseca aos projetos se encontra na ausência de uma perspectiva de longo prazo, uma vez que sua duração é relativamente curta e seu financiamento pontual. Essas características prejudicam a continuidade desses projetos e consequentemente seu alcance enquanto uma proposta alternativa de produção para a região. Nesse contexto, as políticas públicas podem tanto desempenhar um importante papel no estímulo e continuidade a essas propostas ou então representar entraves a esse desenvolvimento.

Como proposto, as experiências estudadas estão em boa medida desconectadas de uma proposta mais ampla e estruturante de mudanças orientadas pelas políticas públicas. A princípio, é visível a dependência dos agricultores com relação aos executores dos projetos para que ofereçam uma consolidada proposta produtiva dos lotes.

Nossa interpretação é de que as atuais políticas públicas voltadas para a agricultura familiar e sua configuração na região apresentam limitações para sustentar o desenvolvimento desses sistemas agroecológicos, mesmo com algumas sinalizações favoráveis, como no caso das políticas de compras institucionais (PAA e PNAE).

Desse modo, é possível pensar que as limitações das políticas públicas susceptíveis de sustentar esses modelos a longo prazo representam uma grande lacuna para sua consolidação. Os agricultores envolvidos manifestam uma sensação de "abandono" após o final dos projetos, pois não vislumbram perspectiva de continuidade seja em termos de assitência técnica, seja em termos de incentivos financeiros ou de comercialização de seus produtos. Esse sentimento pode refletir, mais ou menos intensamente, também no abandono dessas áreas produtivas por parte dos agricultores.

Analisar o papel das políticas públicas nesse contexto evita interpretações sobre limitações e avanços para a concretização da agroecologia nos assentamentos rurais ancoradas apenas no quesito das técnicas produtivas. Sem negar esse aspecto fundamental, que consiste no saber-fazer em torno desses sistemas e no papel decisivo do agricultor enquanto responsável pela produção em seu estabelecimento, é preciso evidenciar também que muitas condições para o sucesso ou insucesso de projetos desse tipo estão enraizadas em processos mais macroestruturais.

\section{REFERÊNCIAS}

ALTIERI, M. Agroecologia: a dinâmica produtiva da agricultura sustentável. $1^{\circ}$ ed. Porto Alegre: UFRGS, 1998. P. 110.

ARL, V. “Agroecologia: desafios para uma condição de interação positiva e co- 
evolução humana na natureza". In: ALVES, A. F; CARRIJO, B, R; CANDIOTTO, L, Z, P. (Org.). Desenvolvimento Territorial e Agroeocologia. São Paulo: Expressão Popular. 2008. p. $155-168$.

BONNAL, P.; LEITE, S. P. (Org.) Análise comparada de políticas agrícolas: uma agenda em transformação. Rio de Janeiro: MauadX, 2011 p. 387.

BORSATTO, R. S.; CARMO, M. S. “A Construção do Discurso Agroecológico no Movimento dos Trabalhadores Rurais Sem-Terra (MST)". RESR, Piracicaba-SP, v. 51, n. 4, p. 645-660, Out/Dez, 2013.

BRASIL. Resolução n⿳012 do MDS de 21 de maio de 2004. Dispõe sobre preços de referência para aquisição dos produtos da agricultura familiar pelo Programa de Aquisição de Alimentos de que trata o artigo 19 da Lei no 10.696, de 02 de julho de 2003. Brasília: Diário Oficial. 24 de mai. 2004.

BRASIL. Lei $\mathbf{N}^{\mathbf{0}} \mathbf{1 2 . 1 8 8}$, de 11 de janeiro de 2010. Institui a Política Nacional de Assistência Técnica e Extensão Rural para a Agricultura Familiar e Reforma Agrária - PNATER e o Programa Nacional de Assistência Técnica e Extensão Rural na Agricultura Familiar e na Reforma Agrária - PRONATER, altera a Lei no 8.666, de 21 de junho de 1993, e dá outras providências. Brasília: Diário Oficial. 12 de jan. 2010.

BRASIL, Decreto $\mathbf{n}^{\circ} 7.794$ de 20 de agosto de 2012. Institui a Política Nacional de Agroecologia e Produção Orgânica. Brasília: Diário Oficial. 21 de ago. 2012.

CANDIOTTO, L. Z. P. “Organic products policy in Brazil”. Land Use Policy, v. 71, p. 422-430, Feb. 2018.

CIAPO - Câmara Interministerial de Agroecologia e Produção Orgânica. Plano Nacional de Agroecologia e Produção Orgânica - PLANAPO. Brasília: MDS/ CIAPO, 2013. p.96.

DITT, E. H. Fragmentos florestais no Pontal do Paranapanema. São Paulo: Annablume, 2002. 140p.

EHLERS, Ed. Agricultura Sustentável - origem e perspectivas de um novo paradigma. São Paulo: Livros da Terra, 1996. p 178. 
FAO/ONU - Food and Agriculture Organization of United Nations. The State of food and agriculture. Rome: FAO/ONU 2017.

FÁVERO, C. "Elaboração participativa do Plano Safra do território da Serra do Brigadeiro, Minas Gerais". Revista Brasileira de Agroecologia, Porto Alegre, v.2, n.2, p. $19-22$. out. 2007.

FELICIANO, C. A. Territórios em disputa: Terras (re)tomadas. Estado, propriedade de terra e luta de classes no Pontal do Paranapanema. 2009. p. 575. Tese (Doutorado em Geografia Humana) - Departamento de Geografia da Faculdade de Filosofia, Letras e Ciências Humanas da Universidade de São Paulo (FFLCH/USP). São Paulo, 2009.

FERNANDES, B. M.; RAMALHO, Cristiane Barbosa. "Luta pela terra e desenvolvimento rural no Pontal do Paranapanema (SP)". Estudos Avançados, São Paulo, v. 15, n. 43. p. 239 - 254, set/dez. 2001.

GANDARA, F. B.; KAGEYAMA, P. Y. Biodiversidade e dinâmica em Sistemas Agroflorestais. In: MACÊDO, J.L.V.; WANDELLI, E.V.; SILVA JÚNIOR, J.P. (Ed.) - III Congresso Brasileiro De Sistemas Agroflorestais (Documentos). 2000. Manaus-AM. Manaus: Embrapa Amazônia Ocidental, 2001. p. 25-32.

GUANZIROLI, C. E. "PRONAF dez anos depois: resultados e perspectivas para o desenvolvimento rural”. Economia e Sociologia Rural. Brasília, v. 45, n. 2, p. 301-328, abr / jun, 2007.

IF/SMA/SP - Instituto Florestal, Secretaria do Meio Ambiente, Governo do Estado de São Paulo - Plano de Manejo: Parque Estadual do Morro do Diabo. Helder Henrique de Faria (coordenador), Santa Cruz do Rio Pardo-SP : Ed. Viena, 2006, $312 \mathrm{p}$.

IPE - Instituto de Pesquisa Ecológicas. Disponível em: http://www.ipe.org.br/ saf/cafe-com-floresta. Acesso em: 10/jul.2018.

LEITE, J. F. A ocupação do Pontal do Paranapanema. São Paulo: Hucitec, 1998. 202p.

LEITE, S. P. “Apresentação”. In: (Org.) Políticas Públicas e Agricultura 
no Brasil. Porto Alegre: UFRGS, 2001. p. 7 - 14.

LE MOAL, M. F. Programa de Aquisição de Alimentos nos assentamentos rurais da reforma agrária, análise sob as lentes da multifuncionalidade da agricultura. 2013. 134p. Dissertação (Mestrado em Ecologia Aplicada) - Escola Superior de Agricultura "Luiz de Queiroz", Universidade de São Paulo, Piracicaba. 2013.

LIMA, J. F. et al. "Café com floresta - criando suficiência alimentar e biodiversidade ecológica". Revista Brasileira de Agroecologia. Porto Alegre, v.2, n.1, p. 301305, Fev. 2007

LOPES, P. R.; KAGEYAMA, P. Y.; ARAÚJO LOPES, K.C.S. "Sistemas agroflorestais e produção agroecológica de café na região do Pontal do Paranapanema". Retratos de Assentamentos. Araraquara, v.17, n.1, p. 261 - 292. Jan/Jun. 2014.

MORAES, M.D. et. al. "Política Nacional de Assistência Técnica e Extensão Rural e o caso da microrregião de Andradina - SP". Retratos de Assentamento. Araraquara, v. 16, n. 2, p. 71 - 90, Jul/Dez. 2013.

NETTO, C. G. A. Mielitz. "A política agrícola brasileira, sua adequação e sua funcionalidade nos vários momentos do desenvolvimento nacional". In: BONNAL, P. e LEITE, S. P (Org.) Análise comparada de políticas agrícolas: uma agenda em transformação. Rio de Janeiro: MauadX, 2011. p. 221 - 252.

OLIVEIRA, A.L. A.; BERGAMASCO, S.M. P. P. "Fortalecimento da agricultura familiar: uma análise do PRONAF no projeto de assentamento São Pedro, Paranaíta, MT". Retratos de Assentamento, Araraquara. v. 17, n. 1, p. 205 - 224, Jan/Jun. 2014.

RODRIGUES, E. R. et. al. "Avaliação econômica de sistemas agroflorestais implantados para recuperação de reserva legal no Pontal do Paranapanema, São Paulo". Rev. Árvore. Viçosa. v.31, n.5, p. 941-948, Set./Out. 2007

SAMBUICHI, R. H. R.; OLIVEIRA, M. A. Constantino. "Análise das linhas de crédito do PRONAF para o desenvolvimento sustentável da agricultura familiar". Cadernos de Agroecologia, Porto Alegre, v. 6, n. 2, Dez. 2011. Disponível em: 
$<$ http://www.aba-agroecologia.org.br/revistas/index.php/cad/article/view/11186> . Acesso em 10 de julho de 2018.

SANTOS, J. D. Desenvolvimento Rural, Biodiversidade e Politicas Públicas: Desafios e antagonismos no Pontal do Paranapanema - SP. 2012, 295 p. Tese (Doutorado em Recursos Florestais) - Escola Superior de Agricultura "Luiz de Queiroz”, Universidade de São Paulo, Piracicaba. 2012.

SOUZA, C. "Políticas Públicas: uma revisão de literatura". Sociologias, Porto Alegre, v. 8, n. 16, p. 20-45, Jul/Dez. 2006.

TAVEIRA, L. R. S.; OLIVEIRA, Julieta Teresa Aier de. "A extensão rural na perspectiva de agricultores assentados do Pontal do Paranapanema-SP”. Economia e Sociologia Rural, Brasília, v. 46, n. 1, p. 09 - 30, Jan/Mar. 2008.

VALENTE, A. L. “A Política Nacional de Assistência Técnica e Extensão Rural e seus desafios". Retratos de Assentamento, Araraquara. v.12, n.1, p. 109 - 124, Jun/Dez. 2009.

WHITAKER, D. C. A. "Reforma Agrária e meio ambiente: Superando o preconceito contra o rural". Retratos de Assentamento, Araraquara. v.12, n.1, p. 33-46, Jun/ Dez. 2009. 